Željko Ljiljak-Vukajlović*

Univerzitet u Beogradu

Filološki fakultet

Doktorand
$811.163 .41 ’ 242-053.4 / .5: 81 ’ 367.625$

https://doi.org/10.18485/zivjez.2021.41.1.1

Originalni naučni rad

Primljen 01/10/2021

Prihvaćen 22/12/2021

\title{
USVAJANJE EPISTEMIČKE I DEONTIČKE MODALNOSTI U SRPSKOM JEZIKU
}

U ovom radu opisani su rezultati eksperimentalnog istraživanja usvajanja deontičke i epistemičke modalnosti koje je obavljeno na uzorku izvornih govornika srpskog jezika (odrasli i deca na uzrastu od 10 godina). Rezultati istraživanja su pokazali da su deca na ovom uzrastu samo delimično usvojila sistem modalnih značenja: iako se u dečjim odgovorima deontička modalnost konstituiše kao zasebna grupa značenja, deca nisu bila u stanju da razlikuju epistemička od deontičkih i dinamičkih modalnih značenja. Za razliku od dece, odrasli ispitanici su bili u stanju da formiraju relativno homogene kategorije značenja i opišu ih na apstraktan način. Međutim, postojanje izraženog efekta konteksta (naročito kod mlađe grupe ispitanika) problematizuje generalizaciju dobijenih rezultata.

Ključne reči: deontička modalnost, epistemička modalnost, usvajanje maternjeg jezika, srpski jezik, međujezičke razlike

\section{Uvod}

U lingvistici se fenomen modalnosti najčešće povezuje sa jezičkim kategorijama koje se koriste za saopštavanje dve osnovne grupe značenja: epistemičkih, kojima se saopštava stav govornika prema istinitosti ili mogućnosti neke propozicije, i deontičkih (ili korenskih) modalnih značenja, kojima se saopštavaju značenja obaveze i dozvole, odnosno neophodnost ili mogućnost vršenja određene radnje (Lions 1977; Palmer 1990; Svitser 1990; Trbojević-Milošević 2004). Pored epistemičke i deontičke modalnosti, neki autori (Palmer 1990; Perkins 1983) razlikuju i treću grupu modalnih značenja - dinamičku modalnost, kojom se izražava (objektivna) sposobnost, volja ili fizička mogućnost za vršenje neke radnje.

Određivanje prema istinitosti i nužnosti neke propozicije (epistemička modalnost) ili uviđanje da postoji obaveza ili nužnost vršenja neke radnje (deontička mo-

Univerzitet u Beogradu, Filološki fakultet, Studentski trg 3, 11000 Beograd; zeljko@ljv.rs 
dalnost) podrazumeva govornika koji poseduje specifične kognitivne kapacitete za apstraktno mišljenje i zaključivanje, odnosno sposobnost za epistemičko i deontičko rezonovanje (Dak i Astington 2011). Bliska povezanost modalnosti sa odgovarajućim kognitivnim procesima, za koje se pretpostavlja da omogućavaju razumevanje i produkciju modalnih oblika i značenja, učinilo je ovu temu pogodnom za praćenje ne samo jezičkog i pojmovnog, već i kognitivnog i socijalnog razvoja dece. Počev od prvih istraživanja, koja su sprovedena krajem sedamdesetih i početkom osamdesetih godina (npr. Vels 1979; Hirst i Vajl 1982), usvajanjem modalnosti u maternjem jeziku bavili su se kako lingvisti, tako i razvojni psiholozi.

Tokom više od tri decenije ispitivanja usvajanja modalnosti u L1 pažnja istraživača iz obe naučne discipline bila je uglavnom usmerena na sledeća pitanja: (1) koji je redosled usvajanja različitih modalnih značenja i oblika i koji kognitivni ili drugi mehanizmi (ako postoje) uslovljavaju takav redosled; (2) kakva je priroda odnosa između usvajanja epistemičke modalnosti i razvoja teorije uma (eng. theory of mind; Miligan et al. 2007) kod dece; i (3) kakva je uloga modalnosti u pragmatskom razvoju i sticanju komunikativnih kompetencija (Papafrago 1998; Choi 2006). Metodološki gledano, istraživanja usvajanja modalnosti mogu se klasifikovati u dve osnovne grupe - opservaciona (longitudinalna i transverzalna) i eksperimentalna istraživanja.

Iako su u fokusu ispitivanja usvajanja modalnosti prevashodno bili indoevropski jezici (Choi 2006), objavljeno je i nekoliko veoma uticajnih istraživanja sa izvornim govornicima neindoevropskih jezika, kao što su korejski, japanski i turski (Choi 1995; Klensi 1985; Aksu-Ko 1988).

Prvi deo ovog rada sadrži pregled teorija kognitivnog razvoja i njihovih implikacija na usvajanje modalnih značenja i jezičkih oblika, kao i osnovne nalaze opservacionih i eksperimentalnih istraživanja usvajanja modalnosti. U drugom delu rada predstavljeni su rezultati eksperimentalnog istraživanja usvajanja modalnosti sprovedenog sa izvornim govornicima srpskog jezika.

\section{Modalnost i klasične razvojne teorije}

Prema klasičnim teorijama kognitivnog razvoja, kao što su Pijažeova i neopijažetanske teorije, kognitivni razvoj traje od rođenja do rane adolescencije (12-15 godina) i može se grubo podeliti u četiri faze: senzomotornu, preoperacionalnu, fazu konkretnih operacija i fazu formalnih operacija (Pjaže 1928, 1987). Okvir Pijažeove teorije, koji omogućava formulisanje konkretnih predviđanja o redosledu usvajanja određenih modalnih značenja, usvojili su i dalje razradili neki istraživači modalnosti, pre svega Perkins (Perkins 1983). Da bi razumeo i koristio modalna 
značenja, govornik mora, prema Perkinsu, posedovati i određena znanja o svetu (Perkins 1983: 151). Razvoj moralnog rasuđivanja, koji predstavlja integralni deo Pijažeove teorije, Perkins dovodi u vezu sa deontičkom modalnošću, dok razvoj apstraktnog mišljenja povezuje sa usvajanjem epistemičke modalnosti.

Perkinsov model usvajanja modalnosti zasniva se na opservacionom istraživanju upotrebe modalnih konstrukcija koje je obavljeno na uzorku od 96 ispitanika uzrasta od šest do 12 godina (Perkins 1983). Modalni oblici se, prema Perkinsu, u dečjem govoru prvi put javljaju u preoperacionalnoj fazi (2-7 godina starosti), koju karakterišu egocentrično mišljenje (nemogućnost deteta da se decentrira od sopstvenog pogleda na svet) i moralni realizam (slepo poštovanje moralnih normi koje se doživljavaju kao apsolutne i nepromenjive; Pjaže 1927, 1987). Deca na ovom uzrastu usvajaju i koriste dinamičke modalne glagole can i will u deontičkom značenju u prvom i drugom licu jednine, a znatno ređe (i na starijim uzrastima) u trećem licu jednine (Perkins 1983). Razvoj logičkog mišljenja i moralnog rasuđivanja prati usvajanje oblika kojim se izražava dinamička i, naročito, deontička modalnost. Najzad, fazu formalnih operacija, koja se javlja na uzrastu od oko 12 godina, karakteriše razvoj apstraktnog mišljenja i deduktivnog zaključivanja, koje Perkins smatra preduslovom za usvajanje epistemičke modalnosti (Perkins 1983). Sposobnost apstrahovanja i mentalnog testiranja alternativnih hipoteza i njihovih implikacija omogućava usvajanje i produktivno korišćenje epistemičkih značenja glagola may i must, te sekundarnih modalnih glagola (could, might, ought to, would, should; Perkins 1983).

Iako se Perkinsov model usvajanja modalnosti zasniva na empirijskim podacima, nalazi naknadno sprovedenih istraživanja nisu potvrdili sva njegova predviđanja. Na primer, kasniji nalazi su potvrdili predviđanja Perkinsove teorije u pogledu redosleda usvajanja modalnih značenja, ali dovode u pitanje predviđanja o uzrastu na kojem se određena značenja usvajanju (Papafrago 1998). Opservaciona istraživanja su pokazala da su deca u stanju da koriste epistemička značenja već tokom treće godine života (Vels 1979; Stefani 1986), znatno ranije nego što Perkinsov model predviđa. Pored toga, neka istraživanja usvajanja evidencijalne modalnosti ukazuju da kognitivni kapaciteti za usvajanje epistemičke modalnosti mogu postojati i na ranom uzrastu (npr. Choi 1995).

\section{Opservaciona istraživanja usvajanja modalnosti}

Nalazi longitudinalnih opservacionih istraživanja spontanog dečjeg govora pokazali su da se, u najvećem broju slučajeva, deontička i dinamička modalna 
značenja usvajaju pre epistemičkih (Vels 1979, 1985). Prema nekim autorima, ranije usvajanje deontičke u odnosu na epistemičku modalnost posledica je veće zastupljenosti deontički modalizovanih iskaza u dečjem govoru i govoru upućenom deci (GUD), kao što su zahtevi i naredbe (Stefani 1993).

Usvajanje modalnih glagola $\mathrm{u}$ engleskom jeziku je postupan i relativno dugotrajan proces koji počinje na uzrastu između 1;10 i 2;6 (Šac i Vilkoks 1991). Prva modalna značenja kojima deca ovladavaju uglavnom su dinamička - namera, želja/odbijanje, mogućnost/nemogućnost, a za izražavanje ovih značenja deca koriste modalne glagole can i will, kao i konkatenative kao što su gonna, wanna, dok je upotreba odričnog oblika can't uglavnom ograničena na izjavne rečenice (Šac i Vilkoks 1991).

Longitudinalna istraživanja sprovedena na većim uzorcima uglavnom su potvrdila ove nalaze. U okviru Bristolske studije jezičkog razvoja (Bristol Language Development Study; Vels 1979, 1985) praćeno je usvajanje jezika kod 60 dečaka i devojčica uzrasta $1 ; 3$ do uzrasta $3 ; 6$, a potom i kod jedne starije grupe dece uzrasta 3;3 do 5;0. Dinamička mogućnost i nemogućnost prva su modalna značenja koja deca usvajaju (can't i can na uzrastu 2;3), dok se modalni oblici kojima se izražava namera (will) usvajaju nekoliko meseci kasnije (na uzrastu 2;6). Deontička značenja (must, have (got) to, should) pojavljuju u dečjem repertoaru oko treće godine. Na uzrastu od 3;3, prosečno dete koje usvaja engleski jezik u stanju je da proizvede gotovo sva dinamička i deontička značenja (Vels 1979). S druge strane, epistemička značenja kojima se saopštava značenje mogućnosti (may i might) takođe se javljaju oko treće godine, ali izuzetno retko. Međutim, tek je svako četvrto dete na uzrastu od 5 godina u stanju da produkuje modalizovane iskaze kojima se saopštava izvesnost (Vels 1985).

Nisku učestalost javljanja epistemičkih upotreba modalnih oblika zabeležili su i drugi autori. U longitudinalnoj studiji slučaja jednog deteta na uzrastu od 1;11 do $3 ; 4$, istraživači su zabeležili samo sedam modalizovanih iskaza sa nedvosmisleno epistemičkim značenjem na uzorku od ukupno 1766 iskaza, od kojih je pet zabeleženo na uzrastu starijem od 2;8 (Pea et al 1982). Međutim, usvajanju epistemičke modalnosti može prethoditi usvajanje gramatičkih markera za glagolsko vreme i glagolski vid, koje deca koriste u igri za označavanje nepostojećih ili zamišljenih situacija. Na primer, kada opisuju zamišljene situacije tokom igre, deca na uzrastu od dve godine kojima je turski prvi jezik koriste evidencijalni sufiks kojim se označava prošlo vreme, dok deca na uzrastu od tri godine kojima je grčki prvi jezik za istu namenu koriste nesvršeno glagolsko vreme (Stefani 1986). Ovi podaci saglasni su sa nalazima drugih istraživanja koja pokazuju da na uzrastu od oko tri godine deca počinju da usvajaju epistemička značenja. 
Opservaciona istraživanja epistemičke modalnosti pokazala su da se prvo usvajaju oblici i konstrukcije kojima se označava izvesnost, a tek potom oblici i konstrukcije kojima se označava manja izvesnost ili neizvesnost. U jednoj longitudinalnoj studiji slučaja analiziran je redosled usvajanja epistemičkih značenja različitih modalnih oblika i konstrukcija u francuskom jeziku (Basano 1996). Rezultati su pokazali da se prvo usvajaju predviđanja (na uzrastu od 2;2), a potom izvesnost (je suis sûr) i izražavanje neznanja (sais pas, na uzrastu 2;5). U periodu od 2;6 do četvrte godine života, dečiji repertoar modalnih oblika i konstrukcija za saopštavanje neizvesnosti postepeno se povećava, zadržavajući isti razvojni pravac od veće izvesnosti ka manjoj (Basano 1996).

U jednoj veoma uticajnoj studiji ispitano je usvajanje evidencijalne modalnosti kod dece kojima je maternji jezik korejski (Choi 1995). Na uzorku od troje korejske dece ispitivano je usvajanje pet evidencijalnih flektivnih sufiksa koji se pojavljuju u neformalnoj komunikaciji, a rezultati su pokazali da su deca u stanju da produktivno koriste određena epistemička značenja i pre treće godine. Prema nalazima ove studije, evidencijalni sufiksi usvajaju se na uzrastu od $1 ; 8$ do $3 ; 0$ fiksnim redosledom, dok se modalni glagoli usvajaju znatno kasnije, na uzrastu od 2;6 do 3;6 (Choi 1995). Rezultati ovog istraživanja često se navode kao dokaz da ne postoje kognitivna ograničenja u usvajanju epistemičkih značenja kod dece mlađe od tri godine (Papafrago 1998). Međutim, odsustvo neepistemičkih značenja i obavezan finalni položaj u rečenici čine ove sufikse netipičnim modalnim oblicima (Choi 1995). Pored toga, ne samo što ispitivana deca nisu usvojila sve modalne sufikse koji postoje u korejskom, već su i usvojeni sufiksi korišćeni u ograničenom broju značenja.

Iako značajni, nalazi opservacionih istraživanja imaju metodoloških nedostataka. Pre svega, dobijeni podaci uglavnom se odnose na jezičku produkciju. Međutim, iako su deca na mlađim uzrastima često u stanju da ispravno produkuju relativno složene jezičke konstrukcije, to ne znači nužno da ih u potpunosti razumeju (Papafrago 1998). Pored toga, većina studija podrazumeva da postoji jasna razlika između dinamičkih, deontičkih i epistemičkih značenja (cf. Papafrago 1998; Choi 2006). Međutim, precizno značenje nekog modalizovanog iskaza nije uvek moguće utvrditi.

\section{Eksperimentalna istraživanja usvajanja modalnosti}

Eksperimentalne studije uglavnom su se bavile usvajanjem epistemičke modalnosti. Jedno od prvih istraživanja ove vrste je eksperimentalna studija usvajanja epistemičkih i deontičkih značenja u engleskom jeziku (Hirst i Vaj1 1982). Cilj ovog 
istraživanja, u kojem je primenjena eksperimentalna paradigma skrivenog predmeta, bio je da se ispita kako deca izrasta od 3;0 do 6;6 razumeju semantičke kontraste između različitih deontičkih i epistemičkih značenja modalnih glagola. Rečenice su sadržale modalne glagole must, should, may i faktualni glagol to be. Rezultati su pokazali da se prvo usvajaju kontrasti sa najvećom razlikom u jačini. Deca na uzrastu od 3;0 do 3;6 razlikuju samo par sa najvećim kontrastom u značenju (is / may), dok deca na uzrastu od četiri godine razlikuju i parove is / should, must / may. Tek na uzrastu od oko pet i po godina deca ovladavaju svim mogućim značenjskim kontrastima. Međutim, najzanimljiviji (i najkontroverzniji) nalaz ovog istraživanja je da deca usvajaju epistemička značenja godinu dana ranije od deontičkih, što je u suprotnosti sa nalazima većine opservacionih istraživanja. Autori upozoravaju da ovaj nalaz treba uzeti sa rezervom zbog veće složenosti deontičkog zadatka, koji je podrazumevao i evaluaciju autoriteta simuliranih likova (Hirst i Vajl 1982: 666).

Kasnija istraživanja potvrdila su ove nalaze o ranijem usvajanju jakih kontrasta i epistemičkih značenja (Mur et al. 1990). Koristeći istu eksperimentalnu tehniku sa lutkama i skrivenim objektom, Mur i saradnici su testirali razumevanje velikog broja modalnih oblika - modalnih glagola, modalnih prideva, modalnih priloga i glagola mentalnih procesa - na uzorku dece uzrasta od tri do šest godina. Za razliku od trogodišnje dece, kojoj modalni kontrasti nisu bili od pomoći u pronalaženju skrivenog predmeta, deca na uzrastu od četiri godine uspevala su da otkriju gde se predmet nalazi. Kao u prethodnoj studiji, deca su bila uspešnija u pronalaženju predmeta kada je značenjski kontrast između modalnih oblika bio veći. Istraživači zaključuju da sposobnost razlikovanja kontrastnih modalnih značenja nije nužno posledica usvajanja leksičkih jedinica, već razvoja kognitivnih kapaciteta za razumevanje mentalnog stanja relativne izvesnosti (Mur et al. 1990).

Nalazi drugih eksperimenata pokazuju da se epistemička značenja usvajaju nešto kasnije. Na primer, u eksperimentalnom istraživanju usvajanja modalnih oblika u francuskom jeziku istraživači su utvrdili da su određene epistemičke modale deca u stanju da razumeju tek na uzrastu od osam godina (Basano et al. 1992). Iako se modalni oblici koji izražavaju izvesnost (npr. je suis sûr) razumeju već na uzrastu od četiri godine, oblike koji izražavaju neizvesnost (npr. je ne suis pas sûr, je crois) deca razumeju tek na uzrastu od osam godina.

Razumevanje modalnih značenja (čak i kod starije dece) ne mora nužno biti ekvivalentno razumevanju odraslog izvornog govornika. U eksperimentu koji se sastojao iz klasifikovanja modalizovanih rečenica prema sličnosti i značenju u proizvoljan broj kategorija, ispitane su tri različite starosne grupe: deca na uzrastu od osam godina, deca na uzrastu od 12 godina i odrasli govornici (Koats, 1988). 
Svaka od modalizovanih rečenica predstavljala je varijaciju rečenice I VISIT my grandmother tomorrow (na primer, I should visit my grandmother tomorrow) $\mathrm{i}$ bila je odštampana na zasebnoj kartici. Rezultati su pokazali da se modalni sistem odraslih izvornih govornika engleskog sastoji od četiri kategorije: epistemičke mogućnosti (npr. may, might, probably); sposobnosti/dozvole (npr. can, be allowed), namere/predviđanja/budućnosti (npr. will, shall, intend) i obaveze/ nužnosti (npr. must, should, ought). Dok na uzrastu od 12 godina deca klasifikuju propozicije slično kao odrasli govornici, na uzrastu od osam godina ne postoji zasebna kategorija za epistemičku modalnost. Ovaj nalaz pokazuje da na uzrastu 8;0 epistemička modalnost nije u potpunosti usvojena (Koats 1988).

U celini uzev, eksperimentalna istraživanja pokazuju da se epistemička i deontička modalnost usvajaju kasnije nego što su to pokazali rezultati opservacionih istraživanja.

\section{Teorijska shvatanja usvajanja modalnosti}

Teorija uma (eng. theory of mind) predstavlja hipotetičku sposobnost dece i odraslih da na metakognitivnom nivou uvide, predvide i objasne sopstvena i mentalna stanja i procese drugih u odnosu na objektivnu realnost (Gopnik i Astington 1988). Razvoj ove kognitivne sposobnosti, smatraju neki autori, uglavnom psiholozi (npr. de Vilije 2007, Miligan et al. 2007), predstavlja minimalni uslov za usvajanje različitih jezičkih kategorija, uključujući i modalnost. Dete određenog uzrasta koje je razvilo implicitnu teoriju uma u stanju je da uoči promene u svojim uverenjima o stanju stvari, da uvidi razliku između sopstvenih uverenja i objektivne realnosti, kao i razliku između sopstvenih i uverenja drugih ljudi (Miligan et al. 2007). Jedan od načina da se ustanovi da li je dete steklo sposobnost uviđanja mentalnih stanja jeste zadavanje zadatka pogrešnog uverenja (eng. false belief task; Gopnik i Astington 1988). Jedna varijanta ovog zadatka sastoji se od pokazivanja predmeta čija je funkcija drugačija nego što to na prvi pogled izgleda (na primer, pernica koja je zapravo bombonjera). Pitanja koja se potom detetu postavljaju testiraju različite aspekte teorije uma: promenu uverenja (šta si mislio/la da je predmet pre nego što si ga otvorio/la), pogrešna uverenja (šta bi druga deca pomislila kada bi videla ovaj predmet) i razlikovanja percepcije od stvarnosti (na šta liči ovaj predmet, a šta u stvari jeste; Gopnik i Astington 1988). Rezultati istraživanja su pokazali da trogodišnja deca nisu u stanju da ispravno odgovore na ova pitanja, dok deca na uzrastu od pet godina jesu (Gopnik i Astington 1988). 
Da ovu kognitivnu sposobnost deca usvajaju na uzrastu od oko 4;0 do 5;0 potvrdio je veći broj istraživanja (npr. Velman et al. 2001). Meta-analiza studija u kojima su korišćeni jezički i zadaci pogrešnog uverenja pokazala je da uspešnost u rešavanju jezičkih zadataka umereno korelira sa uspešnošću u rešavanju zadataka pogrešnog verovanja (koeficijent korelacije 0,43; Miligan et al. 2007). Budući da epistemička modalnost podrazumeva postojanje metakognitivne sposobnosti razmišljanja o sadržaju sopstvenih uverenja i izvođenja logičkih operacija nad njima, mnogi autori smatraju da „teorija uma” predstavlja preduslov za usvajanje epistemičke modalnosti (Papafrago 1998; de Vilije 2007).

Shvatanje da „teorija uma” predstavlja nužan uslov za usvajanje epistemičkih modalnih značenja saglasno je nalazima većine citiranih istraživanja. Kao što su pokazala opservaciona istraživanja usvajanja modalnosti, epistemička značenja se u dečjem govoru prvi put pojavljuju tokom treće godine i to srazmerno retko, a tek na uzrastu od četiri godine počinju da se javljaju češće i u većem broj modalnih konstrukcija (Vels 1979, 1985). Slično tome, eksperimentalna istraživanja su pokazala da uviđanje razlika u značenju modalnih glagola (naročito u stepenu izvesnosti) na uzrastu od oko 5;0 (npr. Hirst i Vajl) odgovara razvojnom periodu u kojem deca ovladavaju sposobnošću uviđanja mentalnih stanja. Dodatnu podršku ovom shvatanju pružaju i nalazi da se glagoli mentalnih procesa (know, think, believe) pojavljuju u dečjem govoru u isto vreme kad i modalni glagoli, odnosno tokom treće godine (Mur et al. 1990).

Iako hipoteza o teoriji uma može da objasni zašto se epistemička značenja usvajaju na uzrastu od četiri godine, ona nije u stanju da objasni zašto se deontička značenja, u dečjem govoru javljaju ranije od epistemičkih. Pored toga, mnoga deontička značenja takođe zahtevaju sposobnost uviđanja mentalnih stanja (na primer, dozvolu, obavezu, itd.; Papafrago 1998). Jedno od mogućih objašnjenja redosleda u usvajanju modalnih značenja je hipoteza da usvajanje modalnosti zavisi od jezičkog inputa kojem su deca izložena. Istraživanja su pokazala da manje od 10\% rečenica govora upućenog deci koje sadrže modalne oblike ima epistemička značenja (Shatz et al. 1990). Slično tome, najčešći modalni glagoli koje su majke u Velsovoj studiji koristile bili su will i can - prvi modalni glagoli koje deca usvajaju (Vels 1979). S druge strane, neki autori (npr. Kamins 1996, 2013) smatraju da postojanje tzv. deontičke prednosti, odnosno empirijskog nalaza da su deca i odrasli uspešniji u zadacima logičkog rasuđivanja koji sadrže deontički autoritet nego u zadacima epistemičkog zaključivanja, predstavlja potvrdu urođenosti deontičkog mišljenja. Prema ovom shvatanju, redosled u usvajanju modalnih značenja bio bi nužna (i nepromenljiva) posledica urođenosti kognitivnog 
subsistema za deontičko rasuđivanje, sa minimalnim uticajem jezičkih faktora (v. Kamins 1996, 2013). Drugi autori osporavaju ovo nativističko stanovište, ističući da je deontička prednost posledica većeg iskustva dece sa društvenim pravilima (Astington i Dak 2013).

Na ovom mestu treba se ukratko osvrnuti i na odnos modalnosti i kognitivnog razvoja, odnosno na pitanje da li usvajanje modalnosti zavisi od opšteg kognitivnog razvoja ili usvajanje modalnosti utiče na kognitivni razvoj. Prema klasičnim (neo)pijažetanskim razvojnim teorijama, razvoj jezika (a samim tim i modalnosti) odvija se paralelno sa kognitivnim razvojem, ali mu ne prethodi (Pjaže 1927, 1987). Međutim, istraživanja su pokazala da je odnos jezika i kognitivnog sistema dinamičan i dvosmeran: u nekim situacijama, sticanje određenih jezičkih veština predstavlja osnovu za dalji razvoj srodnih kognitivnih kapaciteta, dok je u drugim situacijama taj odnos obrnut (Choi 2006). U jednom takvom istraživanju, u kojem je ispitivan odnos razvoja teorije uma i usvajanja sposobnosti da se koriste rečenice kao komplementizatori glagola mentalnih procesa, autori su ustanovili da postoji moguća kauzalna veza između jezičke sposobnosti i razvoja teorije uma (de Vilije i Pajers 1997). S druge strane, u istraživanju logičkog rasuđivanja u kojem su autori poredili uspešnost dece u zadacima jezičkog i nejezičkog rasuđivanja sa deontičkim i modalnim značenjima rezultati su pokazali da sposobnost nejezičkog rasuđivanja predstavlja preduslov za usvajanje epistemičkih modalnih značenja, ali ne i deontičkih (Gonsalves i Falmanje 1999).

\section{Predmet istraživanja}

Iako je literatura o modalnosti u srpskoj lingvistici relativno obimna (za pregled vidi Piper et al. 2005; Hansen 2007), usvajanje različitih oblika modalnosti u srpskom jeziku do sada nije bilo predmet empirijskih istraživanja (Trbojević-Milošević 2004; Prtljaga 2011). Ovo empirijsko istraživanje predstavlja pokušaj da se repliciraju neki od glavnih nalaza iz ove oblasti (npr. Koats, 1988, Basano et al. 1992), uporede rezultati dosadašnjih istraživanja o usvajanju modalnosti sa podacima dobijenim od izvornih govornika srpskog jezika, te dobiju empirijske i metodološke smernice za buduća istraživanja. Shodno tome, ovo istraživanje, koje ima eksploratorni karakter, ne može obuhvatiti sve aspekte fenomena modalnosti u kontekstu usvajanja srpskog kao maternjeg jezika, kao što su kondicionalne klauze, vreme, način i aspekt glagola (cf. Trbojević-Milošević 2004). Kako bi se obezbedila uporedivost nalaza, predmet ovog istraživanja će biti ograničen na modalne glagole i manji broj modalnih priloga i prideva. 
Policentrična klasifikacija modalnih značenja u srpskom jeziku koju neki autori navode (Piper et al. 2005), prema kojoj se deontička i optativna modalnost svrstavaju u objektivnu (realnu, odnosno irealnu) modalnost, a epistemička, imperceptivna, metajezička, aksiološka i ekspresivna modalnost u subjektivne modalnosti, izlazi van okvira ovog istraživanja. U ovom istraživanju biće primenjeno uže shvatanje modalnih značenja, koje obuhvata dinamičku (sposobnost, volja, predviđanje), deontičku (obaveza, dozvola) i epistemičku modalnost (logička nužnost, mogućnost; Perkins 1983, Palmer 1990, 2001). Prema Hansenu (2007: 34-37), pravi modalni glagoli predstavljaju polifunkcionalne izraze modalnosti (u smislu da tipično imaju više od jednog modalnog značenja), a sintaktički se ponašaju kao pomoćni glagoli, dok su polumodalni glagoli ili ograničeni na jedno modalno značenje (npr. deontičko u slučaju imati) ili se sintaktički ponašaju kao leksički glagoli (iako glagol hteti ima veći broj modalnih značenja, u dinamičkom značenju volje on pokazuje sintaktičke osobine leksičkih glagola). Iako većina pravih modalnih glagola ima samo modalna značenja (npr. moći, trebati), neki su zadržali i određena leksička značenja (npr. valjati), te se mogu smatrati hibridnim oblicima (Hansen 2007: 35).

Tabela 1. Modalni glagoli u srpskom jeziku*

\begin{tabular}{|c|c|c|c|c|}
\hline Značenja & Dinamička & Deontička & Epistemička & Pomoćni gl. \\
\hline \multicolumn{5}{|c|}{ Pravi modalni glagoli } \\
\hline moći & $\bullet$ & $\bullet$ & $\bullet$ & $\bullet$ \\
\hline morati & $\bullet$ & $\bullet$ & $\bullet$ & $\bullet$ \\
\hline trebati & $\bullet$ & $\bullet$ & $\bullet$ & $\bullet$ \\
\hline valjati & $\bullet$ & $\bullet$ & & $\bullet$ \\
\hline \multicolumn{7}{|c|}{ Polumodalni glagoli } \\
\hline hteti & & $\bullet$ & $\bullet$ & $\bullet$ \\
\hline smeti & & $\bullet$ & & $\bullet$ \\
\hline imati & & $\bullet$ & & $\bullet$ \\
\hline
\end{tabular}

*Prema Hansen 2007: 37.

Za razliku od modalnih glagola u germanskim jezicima, koji čine jedinstvenu klasu, modalni glagoli u srpskom jeziku su heterogeni kako u pogledu značenja, tako i u pogledu sintaktičkih osobina (tabela 1). 
Cilj ovog istraživanja je bio da se ispita razumevanje dinamičkih, epistemičkih i deontičkih modalnih značenja kod dece - izvornih govornika srpskog jezika na uzrastu od 10 godina i uporedi sa razumevanjem odraslih izvornih govornika srpskog jezika. Ovaj uzrast je odabran kao pogodan iz dva razloga. Prvo, ranija istraživanja sa govornicima engleskog i francuskog jezika su pokazala da deca na uzrastu od osam godina još uvek nisu u potpunosti ovladala epistemičkim modalnim značenjima (Coates 1988; Basano et al. 1992), dok deca na uzrastu od 12 godina pokazuju razumevanje modalnih značenja koje je slično (iako ne identično) razumevanju odraslih (Koats 1988). Drugi razlog se tiče sposobnosti logičkog mišljenja: u većini slučajeva, deca na uzrastu od deset godina poseduju sposobnost induktivnog logičkog rasuđivanja (Pjaže 1927, 1987; Perkins 1983), koja prema rezultatima nekih istraživanja predstavlja preduslov za usvajanje epistemičkih modalnih značenja (Gonsalves i Falmanje 1999). Imajući u vidu nalaze koji su pokazali da čak i na uzrastu od 12 godina (kada se, prema klasičnim razvojnim teorijama, usvaja sposobnost apstraktnog mišljenja) deca nešto drugačije razumeju modalna značenja od odraslih (Koats 1988), postavlja se pitanje kako deca na uzrastima starijim od osam godina, ali koja nisu u potpunosti ovladala sposobnostima za apstraktno mišljenje i deduktivno logičko rasuđivanje, razumeju (pre svega, epistemička) modalna značenja.

U ovom istraživanju su ispitana deontička, dinamička i epistemička modalna značenja pravih modalnih glagola moći, morati, trebati, valjati i polumodalnih glagola smeti, hteti, imati (Hansen 2007). Pored modalnih glagola koje navodi Hansen (2007), ispitana su i dinamička i epistemička modalna značenja polumodalnog glagola umeti, koji Hansen ne smatra modalnim, ali drugi autori navode kao granični slučaj (Trbojević-Milošević 2004). Takođe, u istraživanju su bila zastupljena i neka relativno ređa značenja modalnih glagola, kao što je epistemička upotreba glagola smeti. Najzad, pored razumevanja iskaza sa modalnim glagolima, ispitano je i razumevanje iskaza koji sadrže modalne priloge teško, možda, verovatno, sigurno, moguće (sa epistemičkim značenjima) i neophodno, potrebno, zabranjeno (sa deontičkim značenjima).

\section{Istraživanje}

Ovo istraživanje će pokušati da odgovori na sledeća pitanja: (1) da li, i na koji način, deca - izvorni govornici srpskog jezika na uzrastu od 10 godina razumeju dinamička, epistemička i deontička modalna značenja; (2) da li postoje razlike u razumevanju između dinamičkih, epistemičkih i deontičkih modalnih značenja i 
kakva je priroda tih razlika; i (3) da li postoje i kakva je priroda razlika u razumevanju modalnih značenja između dece i odraslih.

$\mathrm{Na}$ osnovu ranijih istraživanja usvajanja modalnosti očekivali smo da će (1) razumevanje deontičkih značenja biti uspešnije i doslednije od razumevanja epistemičkih značenja (Vels 1985; Kamins 1996); te da će (2) između dece i odraslih postojati razlika u razumevanju epistemičkih modalnih značenja (Koats 1988).

\section{Metod}

U ovom istraživanju je korišćen modifikovani Milerov zadatak sortiranja kartica (Miler 1971). Prvobitna verzija Milerovog zadatka, koja je bila namenjena istraživanju semantičkih sličnosti i razlika, sastojala se od većeg broja kartica na kojima je ispisana po jedna reč (obično imenica), koje se izmešaju da bi redosled kartica bio nasumičan, pri čemu je zadatak ispitanika bio da ih sortira u proizvoljan broj grupa prema značenju. Modifikovana verzija ovog zadatka, koja je korišćena u jednom ranijem istraživanju usvajanja epistemičke modalnosti (Koats 1988), sastojala se od kartica na kojima je, umesto reči, bila ispisana rečenica koja je sadržala jedan od 20 modalnih oblika i fraza (9 modalnih glagola i 11 modalnih priloga i konstrukcija kao što su nothing prevents, possible for, cf. Koats 1988: 428). Kako bi se kontrolisao uticaj sadržaja i konteksta, svaka rečenica je predstavljala varijaciju rečenice I VISIT my grandmother tomorrow (na primer, I can visit my grandmother tomorrow ili It is possible for me to visit my grandmother tomorrow). Kao u slučaju Milerovog zadatka, ispitanicima je davana instrukcija da rečenice sortiraju u proizvoljan broj grupa prema značenjskoj sličnosti. Međutim, ovaj pristup ima dva moguća nedostatka. Zbog korišćenja rečenice-šablona svaki modalni oblik je mogao biti upotrebljen samo jednom, u značenju koje određuje dati kontekst. Druga značenja istog modalnog oblika nije bilo moguće uvrstiti u zadatak, jer bi to podrazumevalo formulisanje dodatnih rečenica, što bi onemogućilo kontrolu konteksta. Pored toga, kao što i sama autorka priznaje (Koats 1988: 427), korišćenje jedne rečenice onemogućava kontrolu polisemije modalnih oblika i fraza. U nekim slučajevima, dati kontekst je omogućavao učitavanje više različitih značenja (kao što je slučaj sa glagolom can u značenjima dozvole i mogućnosti), dok je u drugima favorizovano jedno značenje (npr. must u značenju obaveze).

$\mathrm{U}$ ovom istraživanju je primenjen dijametralno suprotan pristup. Da bi rečenice u eksperimentalnom zadatku obuhvatile što veći broj modalnih značenja, morala je biti napuštena ideja o kontroli uticaja konteksta i sadržaja. Budući da je 
za razumevanje modalnih značenja potreban autentičan kontekst, korišćene su autentične rečenice sa modalnim glagolima moći, morati, trebati, valjati, smeti, hte$t i$, imati, umeti i modalnim prilozima teško, možda, verovatno, sigurno, moguće i neophodno, potrebno, zabranjeno preuzete (u prilagođenom obliku) iz Korpusa savremenog srpskog jezika (SrpKor2013). Spisak korišćenih rečenica priložen je u Dodatku 1. Prikupljen je veći broj rečenica sa epistemičkim, deontičkim i dinamičkim modalnim značenjima, od kojih je za eksperimentalni zadatak odabrano 27. Troje odraslih izvornih govornika srpskog jezika klasifikovalo je prikupljene rečenice u tri grupe modalnih značenja, a samo one oko čijeg značenja je postignut konsenzus uvrštene su u istraživanje.

\section{Ispitanici}

U istraživanju je učestvovalo ukupno 40 ispitanika iz Beograda. Svaki od odraslih ispitanika dao je pisanu saglasnost za učešće u eksperimentu, dok je u slučaju dece za svako dete dobijena prethodna pisana saglasnost roditelja (obrazac za saglasnost roditelja je priložen u Dodatku 2).

Tabela 2. Osnovni podaci o ispitanicima*

\begin{tabular}{|l|c|c|c|}
\hline & \multirow{2}{*}{$\begin{array}{c}\text { Uzorak, } \\
\text { ukupno }\end{array}$} & \multicolumn{2}{|c|}{ Grupa } \\
\cline { 3 - 4 } & 40 & Eksperimentalna & Kontrolna \\
\hline $\mathrm{N}$ & & 20 & 20 \\
\hline Pol & $19 ; 47,5 \%$ & $9 ; 45 \%$ & $10 ; 50 \%$ \\
\hline Muški & $21 ; 52,5 \%$ & $11 ; 55 \%$ & $10 ; 50 \%$ \\
\hline Ženski & $9,7(0,47)$ & $34,4(12,2)$ \\
\hline $\begin{array}{l}\text { Prosečna starost } \\
\text { (godina) }\end{array}$ & & & \\
\hline
\end{tabular}

*Vrednosti u zagradama predstavljaju standardne devijacije.

Ispitanici su birani prema dostupnosti istraživaču, pa se stoga ovaj uzorak mora smatrati prigodnim, a ne reprezentativnim. Ipak, uložen je napor da u uzorku budu zastupljene osnovne demografske kategorije koje su relevantne za predmet ovog istraživanja (vidi tabelu 2). Distribucija ispitanika muškog i ženskog pola približno odgovara prosečnim vrednostima za celokupnu populaciju. Svi ispitanici su izvorni govornici srpskog jezika. 


\section{Procedura}

Istraživanje je izvedeno kao eksperiment sa paralelnim grupama (eksperimentalnom i kontrolnom). Ispitanici su testirani pojedinačno, $u$ individualnim sesijama. Svaki ispitanik je prvo popunio upitnik (vidi Dodatak 3), te dobio kratku usmenu instrukciju i kovertu sa karticama. Svakom ispitaniku je rečeno kartice izvadi iz koverte i promeša ih (kako bi se obezbedio nasumičan redosled rečenica). Ispitaniku je potom rečeno da njegov zadatak da pročita kartice i razvrsta ih u proizvoljan broj grupa prema značenju. Kako bi se kontrolisao uticaj konteksta i sadržaja, ispitanici su dobijali i uputstvo da rečenice koje pripadaju istim ili sličnim oblastima (npr. sport) mogu, ali ne moraju, biti klasifikovane $u$ istu grupu, te da jedini kriterijum za klasifikaciju predstavlja njihova sličnost po značenju. Po završetku sortiranja ispitanici su dobijali uputstvo da svakoj grupi kartica dodele arbitrarni broj i zapišu ga na poleđini svake kartice. Nakon eksperimentalne sesije ispitanici su bili intervjuisani kako bi se prikupili kvalitativni podaci o procesu sortiranja, a tokom intervjua ispitanici su imali i priliku da postave pitanja istraživaču o različitim aspektima istraživanja.

\section{Rezultati}

Statistička obrada podataka obavljena je pomoću softverskog paketa IBM SPSS Statistics (verzija 23). Dobijeni podaci su obrađeni hijerarhijskom klaster analizom, statističkom metodom koja omogućava formiranje homogenih grupa slučajeva, opservacija ili varijabli (Jim i Ramdin 2015). Prosečan broj kategorija modalnih značenja koje su formirali ispitanici prikazan je u tabeli 3.

Tabela 3. Prosečan broj kategorija prema grupi ispitanika i polu

\begin{tabular}{|c|c|c|c|}
\hline Grupa/pol & Raspon & Mod & $\begin{array}{c}\text { Aritmetička } \\
\text { sredina }\end{array}$ \\
\hline $\begin{array}{c}\text { Eksperimentalna } \\
\text { grupa (10 g.) }\end{array}$ & $3-12$ & 4 & 6,95 \\
\hline $\begin{array}{c}\text { Kontrolna grupa } \\
\text { (odrasli) }\end{array}$ & $2-10$ & 5 & 6,00 \\
\hline Muški & $3-12$ & 5 & 6,37 \\
\hline Ženski & $2-10$ & 5 & 6,57 \\
\hline
\end{tabular}


Iako se iz prosečnih vrednosti, iskazanih aritmetičkom sredinom, na prvi pogled čini da je mlađa grupa ispitanika formirala u proseku nešto veći broj kategorija od odraslih ispitanika, ovaj rezultat je posledica malog broja ekstremnih vrednosti (tzv. autlajera), većeg raspona odgovora i manje doslednosti mlađe grupe u odgovorima. Mod, odnosno najčešća vrednost, pokazuje da je većina odraslih ispitanika formirala jednu grupu više od dece na uzrastu od 10 godina, dok je raspon broja kategorija u odgovorima na približno jednakom nivou. Gledano po polu, nisu zabeležene veće razlike između ispitanika muškog i ženskog pola, kako na nivou celog uzorka, tako i na nivou grupa.

Odgovori ispitanika u eksperimentalnoj grupi (deca na uzrastu od 10 godina) pokazuju veću varijabilnost i formiraju manji broj slabije definisanih klastera u odnosu na kontrolnu grupu (grafikon 1).

Grafikon 1. Dendrogram modalnih značenja (eksperimentalna grupa)

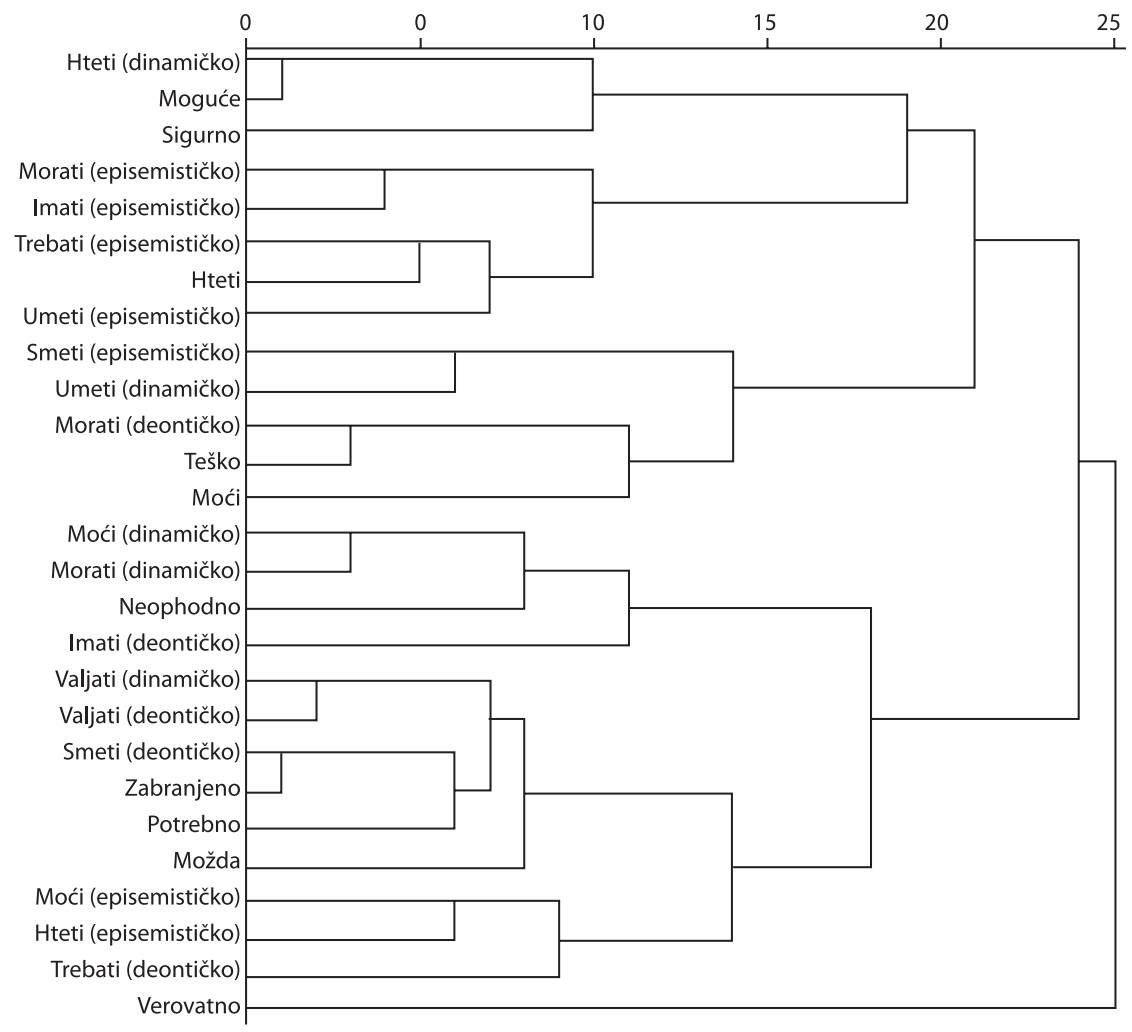


$\mathrm{Na}$ dendrogramu odgovora dece mogu se uočiti tri klastera modalnih značenja, sa slabijim vezama između konstituentnih značenja nego što je to bio slučaj kod odraslih ispitanika (duža grananja predstavljaju grafički prikaz slabije povezanosti). Dok odrasli ispitanici epistemička značenja grupišu u dva klastera od mogućih četiri, kod mlađe grupe ispitanika epistemička značenja su prisutna u svim klasterima. Slično tome, u dečjim odgovorima nije moguće uočiti značenjske obrasce ni kada su u pitanju deontička i dinamička modalna značenja, što bi moglo ukazivati da deca - izvorni govornici srpskog jezika na ovom uzrastu nisu u stanju da razlikuju epistemička, s jedne strane, i deontička i dinamička modalna značenja, s druge.

Dečiji odgovori pokazuju znatno veću varijabilnost u pogledu broja formiranih grupa: dok su odrasli u proseku pravili oko 5 grupa značenja, pri čemu su ekstremne vrednosti bile retke, odgovori dece su bili polarizovani oko ekstremnih vrednosti. Deca su takođe bila manje dosledna u odgovorima od odraslih ispitanika.

Dendrogram modalnih značenja kontrolne grupe (odrasli izvorni govornici srpskog jezika) prikazan je na grafikonu 2. Odgovori odraslih ispitanika formiraju četiri klastera modalnih značenja:

obaveza/zabrana (modalni glagoli smeti, trebati, hteti u deontičkim i dinamičkim značenjima, modalni prilozi zabranjeno, potrebno u deontičkim značenjima)

epistemička nužnost/epistemička mogućnost/sposobnost/dozvola (modalni glagol moći (epistemičko i deontičko značenje), epistemičko hteti, smeti, trebati, dinamičko umeti);

objektivna mogućnost/nužnost (modalni glagoli valjati, moći, imati u dinamičkim i deontičkim značenjima);

volja/epistemička mogućnost/izvesnost (epistemički modalni prilozi i pridevi možda, sigurno, verovatno, moguće, modalni glagoli hteti u dinamičkom i morati u epistemičkom značenju).

Između članova klastera značenja postoji relativno bliska povezanost, sa izuzetkom polumodalnog glagola umeti u epistemičkom značenju, koji je slabo povezan sa prvom kategorijom modalnih značenja. Zanimljivo je da kod testirane grupe odraslih govornika epistemička značenja ne predstavljaju zasebnu grupu značenja, već su distribuirana u dve grupe unutar kojih se kombinuju sa dinamičkim značenjem volje (klaster 4) i deontičkim značenjem dozvole (klaster 2). S druge strane, deontička i dinamička značenja predstavljaju jasno definisane kategorije (klasteri 1 i 3). 
Grafikon 2. Dendrogram modalnih značenja (kontrolna grupa)

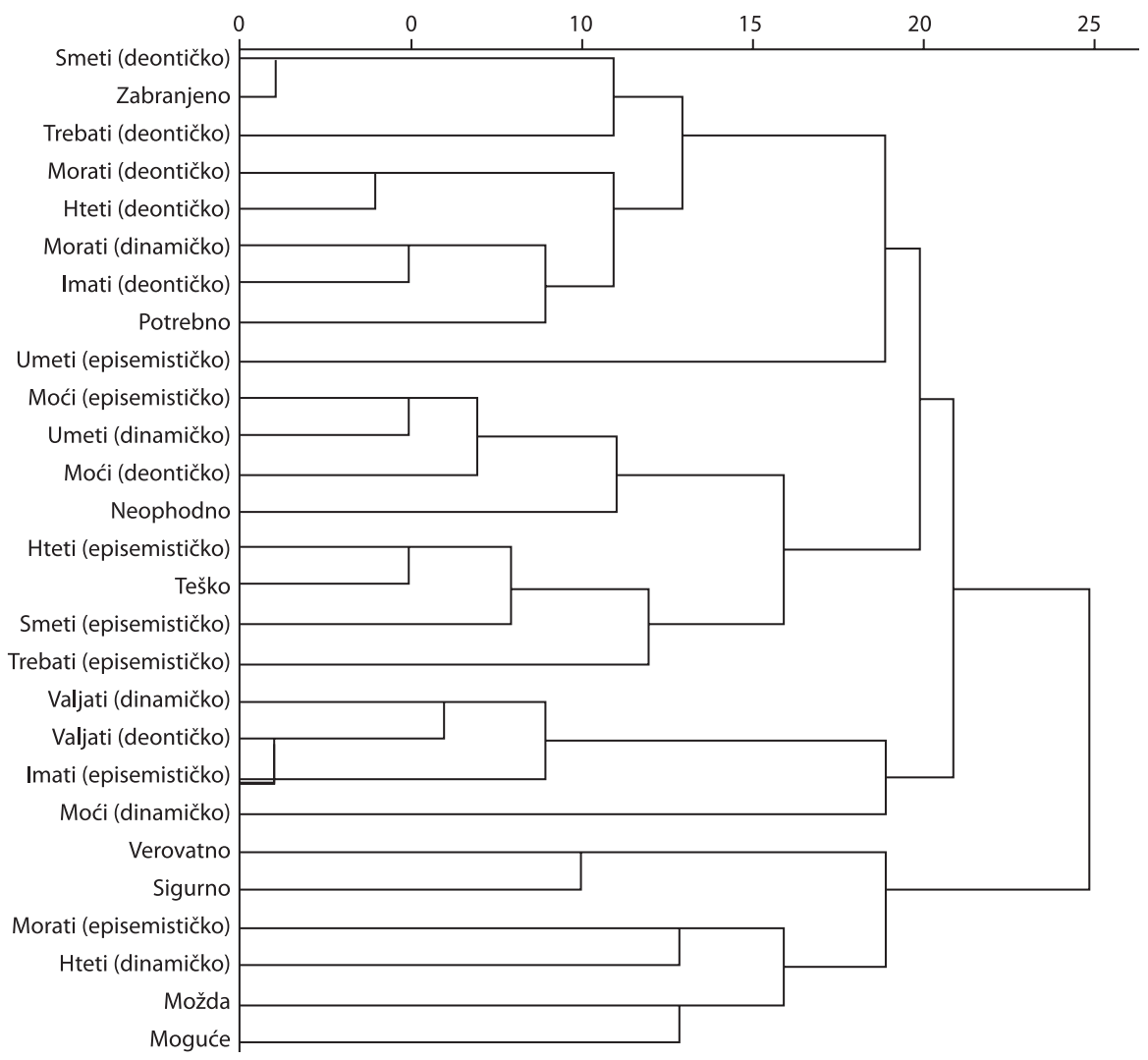

Debrifing obavljen sa svakim ispitanikom po završetku eksperimentalne sesije pruža delimičan uvid u strategije korišćene tokom rešavanja zadatka. Naime, dok su odrasli ispitanici svoje kategorije opisivali apstraktnim nazivima kao što su ,pretpostavke”, „obaveze”, ,pravila”, ,namera”, ,naredbe i dozvole”, ,preporuke”, ,mogućnost”, deca u većini slučajeva nisu bila u stanju da jasno opišu kategorije koje su definisala ili su ih definisala prema sadržaju rečenica, npr. „sport”, „opšte istine”, ,putovanja”, ,geografija” i slično. Izuzetak su bila deontička značenja dozvole i obaveze, koja su deca uočavala kao „naredbe” i „pravila”. Ova razlika ukazuje na delovanje efekata konteksta i sadržaja, naročito kod mlađe grupe ispitanika. 
Treba primetiti da ni u odgovorima kontrolne grupe epistemička značenja nisu formirala zaseban klaster, već su bila distribuirana u dva klastera sa većinskim epistemičkim značenjima. S druge strane, deontička (i dinamička) značenja su formirale jasno definisane klastere, što je nalaz koji potvrđuje prvu istraživačku hipotezu i ranije nalaze o razvojnoj i kognitivnoj primarnosti deontičkog naspram epistemičkog mišljenja (Kamins 1996, Beller 2008). Zanimljivo je da je i u kontrolnoj grupi zabeležen relativno nizak stepen saglasnosti u klasifikaciji modalnih značenja između ispitanika, koje mogu biti posledica individualnih razlika ili nekog drugog faktora.

\section{Zaključak}

Dobijeni nalazi potvrdili su obe istraživačke hipoteze. Čini se da deca - izvorni govornici srpskog jezika na uzrastu od deset godina nisu u potpunosti usvojila sistem modalnih značenja. Pre svega, nisu u stanju da dosledno razlikuju epistemička od deontičkih i dinamičkih modalnih značenja. U odgovorima eksperimentalne grupe epistemička značenja ne predstavljaju zasebnu grupu modalnih značenja. Ovi nalazi potvrđuju Perkinsovu teoriju o usvajanju modalnosti, prema kojoj se usvajanje sistema modalnih značenja u maternjem jeziku finalizuje u fazi formalnih operacija, odnosno na uzrastu od 12 godina (Perkins, 1983), kao i nalaze eksperimentalnih studija koje su pokazale da se deontička modalnost usvaja pre epistemičke (Basano et al. 1992, Koats 1998). Još važnije, dobijeni rezultati predstavljaju potvrdu hipoteze o primarnosti deontičkog mišljenja nad epistemičkim (Kamins 1996, 2013). Čini se da, makar na uzrastu od 10 godina, izvorni govornici srpskog jezika još uvek nisu u potpunosti usvojili sve oblike modalnosti, što sugeriše da je preduslov usvajanja epistemičke modalnosti usvajanje sposobnosti apstraktnog mišljenja u fazi formalnih operacija.

Kada je reč o deontičkim i dinamičkim značenjima, u najvećem broju slučajeva deca na ovom uzrastu uočavaju da je reč o dozvolama i obavezama, a u znatno manjoj meri sposobnostima u mogućnostima. Zapravo, u odgovorima eksperimentalne grupe jedino se deontička značenja mogu izdvojiti u zasebnu kategoriju modalnih značenja. Iako su ovi nalazi očekivani i predstavljaju potvrdu teorija i hipoteza koji predviđaju uspešnije i doslednije razumevanje deontičkih značenja u poređenju sa epistemičkim, te primarnost deontičkog nad epistemičkim mišljenjem (Vels 1985; Kamins 1996, 2013), oni u podjednakoj meri validiraju i alternativne hipoteze o usvajanja modalnih značenja, pre svega onu prema kojoj jezički input kojem su deca izložena (jezik zabrana i pravila) određuje redosled usvajanja modalnih značenja (Astington i Dak 2013, Šac et al. 1990). 
Prema hipotezi o „teoriji uma”, ispitanici u eksperimentalnoj grupi (deca na uzrastu od 10 godina) treba da su u potpunosti ovladala ovom sposobnošću (Velman et al. 2001). S obzirom da predviđa razumevanje epistemičkih modalnih značenja na uzrastu mlađem od uzrasta dece u eksperimentalnoj grupi, hipoteza o „teoriji uma” ne može objasniti nalaze ovog istraživanja, koji pokazuju da se deontička značenja prepoznaju kao zasebna grupa, dok sa epistemičkim to nije slučaj. Iako se u eksperimentalnoj grupi deontički modalizovani stimulusi mogu identifikovati kao zasebna grupa, treba naglasiti da je zabeležen nizak stepen saglasnosti između ispitanika, što se može videti na dendrogramu (grafikon 1). Nizak stepen saglasnosti može biti posledica razlika između ispitanika (bilo individualnih bilo razvojnih), ali i korišćenja prigodnog uzorka.

Za razliku od dece, odrasli ispitanici su bili u stanju ne samo da formiraju relativno homogene kategorije značenja, već i da ih opišu koristeći apstraktne nazive, koji su ukazivali na to da li se radi o realnim i nerealnim propozicijama (,pretpostavke”, „mogućnost”) ili o obavezama i dozvolama. Ovaj nalaz je saglasan sa drugom istraživačkom hipotezom, koja je predviđala postojanje razlika u razumevanju epistemičkih modalnih značenja između dve grupe ispitanika i nedvosmisleno ukazuje na tesnu vezu sposobnosti za apstraktno mišljenje i modalnih značenja, naročito epistemičkih (Perkins 1983).

Rezultati ovog istraživanja donekle odstupaju od rezultata drugih sličnih istraživanja (npr. Koats 1988, u kojem je primenjena slična metodologija), pre svega u pogledu kategorije epistemičke modalnosti, koja je bila jasnije definisana u odgovorima odraslih ispitanika i odvojena od drugih modalnih značenja. Postoje dva moguća razloga za ovo odstupanje. Za razliku od engleskog (i drugih germanskih) jezika, modalni glagoli u srpskom jeziku ne predstavljaju homogen sistem sa jedinstvenim morfosintaktičkim obeležjima, već relativno heterogenu grupu modalnih, polumodalnih i leksičkih glagola (Hansen 2007), što je moglo uticati na formiranje klastera i prema gramatičkim (npr. morfosintaktičkim), a ne samo čisto semantičkim obeležjima. Drugi mogući razlog predstavlja postojanje efekata konteksta i sadržaja, koji su u ranijim istraživanjima bili kontrolisani u većoj meri (Koats 1988). Efekat konteksta je naročito bio izražen kod mlađe grupe ispitanika, ali je zabeležen i kod odraslih ispitanika. Uticaj konteksta na razumevanje modalizovanih iskaza ostaje tema za neko buduće istraživanje.

Pored zabeleženog efekta konteksta, ovo istraživanja ima i druga metodološka ograničenja. Pre svega, istraživanje je sprovedeno sa jednom uzrasnom grupom. Kako bi se dobila potpunija slika o procesu usvajanja modalnosti na različitim uzrastima, potrebno sprovesti istraživanje sa većim brojem uzrasnih grupa ili 
istraživanje longitudinalnog tipa. Istraživanje je obavljeno na prigodnom uzorku, što mu nužno daje eksploratorni karakter i ograničava generalizaciju dobijenih rezultata. Slično tome, statistička tehnika koja je korišćena u istraživanju omogućava donošenje zaključaka o grupnim preferencijama, ali ne pruža uvid u individualne razlike u razumevanju modalnih značenja, koje mogu biti veće od grupnih. Individualne razlike u razumevanju (naročito epistemičkih) modalnih značenja predstavljaju posebno zanimljiv aspekt fenomena modalnosti u jeziku, a nalazi ovog i sličnih istraživanja ukazuju da postoje razlike između izvornih govornika kako u razumevanju, tako i u produkciji modalnih značenja. Pored toga, sam eksperimentalni zadatak je moguće poboljšati uvođenjem kontrolnih nemodalizovanih iskaza, koji bi služili za kontrolu klasifikacije u zadatku sortiranja.

\section{LITERATURA}

Aksu-Koć 1988: A. Aksu-Koç, The acquisition of aspect and modality: The case of past reference in Turkish. New York: Cambridge University Press.

Astington i Dak 2013: J. W. Astington \& L. A. Dack, Development of the deontic advantage in reasoning: reply to Cummins. Journal of experimental child psychology, 116(3), 770-773.

Basano 1996: D. Bassano, Functional and formal constraints on the emergence of epistemic modality: a longitudinal study on French. First Language, 16(46), 077-113.

Basano et al. 1992: D. Bassano, M. Hickmann, C. Champaud, Epistemic modality in French children's discourse: to be sure or not to be sure? Journal of Child Language, 19(02), 389-413.

Beler 2008: S. Beller, Deontic norms, deontic reasoning, and deontic conditionals. Thinking \& Reasoning, 14(4), 305-341.

Beler 2010: S. Beller, Deontic reasoning reviewed: psychological questions, empirical findings, and current theories. Cognitive processing, 11(2), 123-132.

Čoi 1995: S. Choi, The Development of Epistemic Sentence-ending Modal Forms and Functions in Korean Children. In J. Bybee \& S. Fleischman (eds), Modality in Grammar and Discourse, Amsterdam: John Benjamins, 165204.

Čoi 2006: S. Choi, Acquisition of modality. In W. Frawley (Ed.), The expression of modality, Berlin: Walter de Gruyter,141-171.

Dak i Astington 2011: L. A. Dack \& J. W. Astington, Deontic and epistemic reasoning in children. Journal of experimental child psychology, 110(1), 94-114. 
Gonsalves i Falmanje 1999: J. Gonsalves \& R. Falmagne, Cognitive prerequisites for modal verb acquisition. In Boston University Conference on Language Development 1999-23-P, 204-215.

Gopnik i Astington 1988: A. Gopnik \& J. W. Astington, Children's understanding of representational change and its relation to the understanding of false belief and the appearance-reality distinction. Child Development, 59(1), 26-37.

Hansen 2007: B. Hansen, A Morpho-syntactic Typology of Constructions with Modals in Serbian. U: J. Грковић-Мејџор, В. Ружић, С. Павловић (ur.), Синтаксичка истражсивања (дијахроно-синхрони план). Нови Сад: Филозофски факултет

Hirst i Vajl 1982: W. Hirst \& J. Weil, Acquisition of epistemic and deontic meaning of modals. Journal of Child Language, 9(03), 659-666.

Jim i Ramdin 2015: O. Yim \& K. T. Ramdeen, Hierarchical cluster analysis: Comparison of three linkage measures and application to psychological data. Quantitative Methods in Psychology, 11(1), 8-24.

Kamins 1996: D. D. Cummins, Evidence of deontic reasoning in 3- and 4-yearold children. Memory \& Cognition, 24(6), 823-829.

Kamins 2013: D. D. Cummins, Deontic and epistemic reasoning in children revisited: comment on Dack and Astington. Journal of experimental child psychology, 116(3), 762-769.

Klensi 1985: P. M. Clancy, The acquisition of Japanese. In D. I. Slobin (Ed.), The crosslinguistic study of language acquisition, 2 vols, Hillsdale, NJ: Lawrence Erlbaum Associates, 373-524.

Koats 1988: J. Coates, The acquisition of the meanings of modality in children aged eight and twelve. Journal of Child Language, 15(02), 425-434.

Lions 1977: J. Lyons, Semantics (Vol. 2). Cambridge, New York: Cambridge University Press.

Miler 1971: G. A. Miller, Empirical methods in the study of semantics. In: D. Steinberg \& L. A. Jacobovits (Eds), Semantics: an interdisciplinary reader in philosophy, linguistics and psychology, Cambridge: Cambridge University Press, 569-585.

Miligan et al. 2007: K. Milligan, J. W. Astington, L. A. Dack, Language and theory of mind: meta-analysis of the relation between language ability and false-belief understanding. Child development, 78(2), 622-646.

Mur et al. 1990 C. Moore, K. Pure, D. Furrow, Children's understanding of the modal expression of speaker certainty and uncertainty and its relation to 
the development of a representational theory of mind. Child Development, 61(3), 722-730.

Palmer 1990: F. R. Palmer, Modality and the English modals (2nd ed.). London, New York: Longman.

Palmer 2001: F. R. Palmer, Mood and modality. Cambridge: Cambridge University Press.

Papafrago 1998: A. Papafragou, The Acquisition of Modality: Implications for Theories of Semantic Representation. Mind and Language, 13(3), 370-399.

Perkins 1983: M. R. Perkins, Modal expressions in English. London: Burns \& Oates.

Piper et al. 2005: P. Piper, I. Antonić, R. Ružić, S. Tanasović, Lj. Popović, B.

Tošović, Sintaksa savremenog srpskog jezika - prosta rečenica. Beograd:

SANU - Beogradska knjiga - Matica srpska.

Pjaže 1928: J. Piaget, Judgement and reasoning in the child. London: Routledge.

Pjaže 1987: J. Piaget, Possibility and necessity (2 vols.). Minneapolis: University of Minnesota Press.

Prtljaga 2011: J. Prtljaga, Deontička modalnost u engleskom i srpskom jeziku.

Ddoktorska disertacija. Univerzitet u Novom Sadu, Filozofski fakultet, Novi Sad.

Šac et al. 1990: M. Shatz, H. Grimm, S. Wilcox, K. Niemeier-Wind, Modal Expressions in German and American Mother-Child Conversations: Implications for Input Theories of Language Acquisition. Unpublished article, Ann Arbor: University of Michigan.

Šac i Vilkoks 1991: M. Shatz \& S. Wilcox, Constraints on the Acquisition of English Modals. In S. Gelman \& J. Byrnes (eds), Perspectives on Language and Thought, Cambridge: Cambridge University Press, 319-353.

Stefani 1986: U. Stephany, Modality. In: P. Fletcher \& M. Garman (Eds), Language acquisition: Studies in first language development, Cambridge: Cambridge University Press, 375-400.

Stefani 1993: U. Stephany, Modality in First Language Acquisition: The State of the Art. In N. Dittmar \& A. Reich (Eds.), Modality in Language Acquisition / Modalité et acquisition des langues, Berlin, New York: De Gruyter, 133-144.

Svitser 1990: E. Sweetser, From etymology to pragmatics: Metaphorical and cultural aspects of semantic structure. Cambridge - New York: Cambridge University Press. 
Trbojević-Milošević 2004: I. Trbojević-Milošević, Modalnost, sud, iskaz: Epistemička modalnost $u$ engleskom i srpskom jeziku. Beograd: Filološki fakultet.

de Vilije 2007: J. de Villiers, The Interface of Language and Theory of Mind. Lingua, 117(11), 1858-1878.

de Vilije i Pajers 1997: J. de Villiers, J. Pyers, Complementing cognition: The relationship between language and theory of mind. In Proceedings of the 21st Annual Boston University Conference on Language Development, Somerville, MA: Cascadillia Press, 136-147.

Velman et al. 2001: H. M. Wellman, D. Cross, J. Watson, Meta-analysis of theory-of-mind development: the truth about false belief. Child development, 72(3), 655-684.

Vels 1979: G. Wells, Learning and using the auxiliary verb in English. In V. Lee (Ed.), Language Development. London: Croom Helm, 250-270.

Vels 1985: G. Wells, Language Development in the Pre-school Years. Cambridge: Cambridge University Press. 


\title{
Željko Ljiljak-Vukajlović
}

\section{ACQUISITION OF EPISTEMIC AND DEONTIC MODALITY IN SERBIAN}

\begin{abstract}
Summary
This paper describes the results of an experimental study of the acquisition of deontic and epistemic modality performed on a sample consisting of adult and ten-year-old native speakers of Serbian. The results showed that at this age children had only partially acquired the system of modal meanings: although deontic modality constituted a separate group of meanings in their responses, the children were unable to distinguish epistemic from deontic and dynamic modal meanings. On the other hand, adult respondents were able to generate relatively homogeneous categories of meaning and describe them in abstract terms. However, the presence of marked context effect (to which younger respondents were particularly susceptible) may limit finding generalizability.
\end{abstract}

Keywords: deontic modality, epistemic modality, first language acquisition, Serbian language, cross-linguistic differences. 
Dodatak 1. Spisak rečenica koje su korišćene u istraživanju

\begin{tabular}{|c|c|c|}
\hline $\begin{array}{l}\text { Modalni } \\
\text { glagoli }\end{array}$ & Primeri & $\begin{array}{l}\text { Modalno } \\
\text { značenje }\end{array}$ \\
\hline \multirow{4}{*}{ moći } & Ventilator može raditi na baterije ili na struju. & Dinamičko \\
\hline & & \\
\hline & Birač može glasati samo za jednu izbornu listu. & Deontičko \\
\hline & Pušenje može imati štetne posledice po zdravlje. & Epistemičko \\
\hline \multirow{3}{*}{ morati } & Ubuduće će TV pretplata morati da se plaća. & Deontičko \\
\hline & Za veću ocenu moraš više da se trudiš. & Dinamičko \\
\hline & Taj ključić mora biti od nekih vrata u hodniku. & Epistemičko \\
\hline \multirow[t]{2}{*}{ trebati } & $\begin{array}{l}\text { Nepušačka zona treba da bude smeštena blizu } \\
\text { vrata. }\end{array}$ & Deontičko \\
\hline & Deca treba da su već stigla iz škole. & Epistemičko \\
\hline \multirow[b]{2}{*}{ valjati } & Do mora valja pešačiti nizbrdo pa uzbrdo. & Dinamičko \\
\hline & $\begin{array}{l}\text { Umesto slatkiša valja jesti što više povrća i } \\
\text { svežeg voća. }\end{array}$ & Deontičko \\
\hline \multirow{3}{*}{ hteti } & Rusi hoće da do 2030. slete na Mars. & Dinamičko \\
\hline & Kad se vratim, hoću da sve bude na svom mestu. & Deontičko \\
\hline & Prehlada hoće dugo da traje kad se ne leči. & Epistemičko \\
\hline \multirow{2}{*}{ imati } & Prava potrošača imaju biti zaštićena zakonom. & Deontičko \\
\hline & Napolju pljušti - ima da pokisnemo kao miševi. & Epistemičko \\
\hline \multirow{2}{*}{ smeti } & $\begin{array}{l}\text { Pešak ne sme da prelazi ulicu van pešačkog } \\
\text { prelaza. }\end{array}$ & Deontičko \\
\hline & $\begin{array}{l}\text { U prvom kolu kvalifikacija ne bi smelo da bude } \\
\text { iznenađenja. }\end{array}$ & Epistemičko \\
\hline \multirow[b]{2}{*}{ umeti } & Đoković ume da igra i na travi. & Dinamičko \\
\hline & $\begin{array}{l}\text { U metrou ujutru i popodne ume da bude užasna } \\
\text { gužva. }\end{array}$ & Epistemičko \\
\hline
\end{tabular}




\begin{tabular}{|l|l|}
\hline $\begin{array}{l}\text { Drugi } \\
\text { modalni } \\
\text { oblici }\end{array}$ & Primeri \\
\hline $\begin{array}{l}\text { prilozi/ } \\
\text { pridevi }\end{array}$ & Ovakav uspeh teško da će biti ponovljen. \\
\cline { 2 - 3 } & $\begin{array}{l}\text { Pingvine su izuzetne ronilačke veštine možda koštale } \\
\text { sposobnosti letenja. }\end{array}$ \\
\cline { 2 - 3 } & $\begin{array}{l}\text { Naselje Janoš je verovatno dobilo ime po svom crkvenom } \\
\text { zaštitniku. }\end{array}$ \\
\cline { 2 - 3 } & $\begin{array}{l}\text { Barselona je sigurno jedna od najpopularnijih turističkih } \\
\text { destinacija. }\end{array}$ \\
\cline { 2 - 3 } & $\begin{array}{l}\text { Moguće je da u kosmosu postoje milioni planeta na kojima se } \\
\text { razvio život. }\end{array}$ \\
\cline { 2 - 3 } & $\begin{array}{l}\text { Za učešće na maratonu neophodno je da takmičar poseduje } \\
\text { fzičku spremu. }\end{array}$ \\
\cline { 2 - 3 } & $\begin{array}{l}\text { Po preuzimanju karata potrebno je da obavite čekiranje i } \\
\text { pasošku kontrolu. }\end{array}$ \\
\cline { 2 - 3 } & Zabranjeno je skijati po zatvorenoj stazi. \\
\hline
\end{tabular}




\section{Dodatak 2. Formular za saglasnost roditelja ili staratelja}

Poštovani roditelji,

Želeli bismo da pozovemo Vaše dete da učestvuje u istraživanju o usvajanju modalnih glagola u srpskom jeziku, koje se sprovodi u okviru doktorskih studija iz lingvistike na Filološkom fakultetu u Beogradu. Vaše dete smo odabrali kao mogućeg učesnika jer pripada uzrasnoj grupi koju želimo da ispitamo. Molimo Vas da pažljivo pročitate ovaj formular i, ukoliko ste saglasni sa učešćem Vašeg deteta u ovom istraživanju, svoju saglasnost potvrdite potpisom u odgovarajućem polju.

Opis istraživanja. Cilj ovog istraživanja je da se ispita kako deca na uzrastu od 10 godina razumeju značenja modalnih glagola MOĆI, MORATI, TREBATI, VALJATI, SMETI, HTETI, IMATI i kako se njihovo razumevanje tih glagola razlikuje od razumevanja odraslih govornika srpskog jezika. Modalni glagoli predstavljaju posebnu grupu glagola koja je u bliskoj vezi sa opštim kognitivnim razvojem deteta, a naročito sa razvojem sposobnosti za apstraktno mišljenje. Modalnim glagolima se, na primer, saopštava stav govornika prema istinitosti neke propozicije ili neophodnost/mogućnost vršenja neke radnje.

Tok istraživanja. Vaše dete će dobiti 27 kartica na kojima je odštampana po jedna rečenica (na primer, „Alisa je pomislila da taj ključić mora biti od nekih vrata u hodniku."), a njegov/njen zadatak će biti da ih razvrsta u proizvoljan broj grupa prema značenju.

Poverljivost. Ovo istraživanje je anonimno, a prikupljeni podaci će se smatrati poverljivim. Jedini podaci koji se prikupljaju su uzrast i pol deteta.

Dobrovoljnost. Učešće u istraživanju je dobrovoljno i imate pravo da u bilo kom trenutku odustanete od daljeg učešća. Pored toga, Vaše dete takođe ima pravo da u bilo kom trenutku odustane od daljeg učešća.

Ako imate bilo kakvih dodatnih pitanja o istraživanju, obratite se istraživaču na adresu:

Zahvaljujemo na Vašem vremenu i spremnosti na saradnju.

Srdačno,

Saglasan sam da moje dete

učestvuje u istraživanju o usvajanju modalnih glagola u srpskom jeziku.

Potpis roditelja ili staratelja 


\section{Dodatak 3. Upitnik za odrasle ispitanike}

Poštovani/a,

Želeli bismo da Vas pozovemo da učestvujete u lingvističkom istraživanju koje se sprovodi u okviru doktorskih studija iz lingvistike na Filološkom fakultetu u Beogradu. Molimo Vas da pažljivo pročitate ovaj formular i, ukoliko ste saglasni sa učešćem u ovom istraživanju, svoju saglasnost potvrdite potpisom u odgovarajućem polju.

Opis istraživanja. Cilj ovog istraživanja je da se ispita kako odrasli govornici razumeju određene jezičke iskaze kojima se saopštava stav govornika.

Tok istraživanja. Dobićete 27 kartica na kojima je odštampana po jedna rečenica (na primer, „Alisa je pomislila da taj ključić mora biti od nekih vrata u hodniku."), a Vaš zadatak će biti da ih razvrstate u proizvoljan broj grupa prema značenju.

Poverljivost. Ovo istraživanje je anonimno, a prikupljeni podaci će se smatrati poverljivim. Jedini podaci koji se prikupljaju su pol i godine starosti.

Dobrovoljnost. Učešće $u$ istraživanju je dobrovoljno i imate pravo da u bilo kom trenutku odustanete od daljeg učešća.

Saglasnost. Vašim potpisom potvrđujete da ste razumeli informacije o eksperimentu i dajete svoj pristanak na učešće u njemu.

Ispitanik

Istraživač
Datum

Datum

\section{Opšti podaci (zaokružite ili upišite odgovor):}

Pol

Koliko imate godina? (upišite) 